\title{
EL ENVEJECIMIENTO Y LA MUERTE: UN ENFOQUE FILOSÓFICO
}

\author{
AGING AND DEATH: A PHILOSOPHICAL APPROACH
}

Marco Jiménez Alfaro*

\begin{abstract}
RESUMEN
En este ensayo, el autor reflexiona acerca del tema del envejecimiento y su relación focal con la idea de la muerte. Para este propósito integra previamente información histórica y científica, para luego culminar en la complementaria valoración filosófica, objeto del ensayo. En la primera parte se explica las distintas concepciones de la vejez que han predominado en el tiempo, destacando los casos paradigmáticos como antagónicos de Platón y Aristóteles, quienes serían la principal empresa interpretativa de posteriores versiones hasta la actualidad. En la segunda parte, se realiza en forma interrogativa un breve análisis de los conceptos de longevidad y envejecimiento, que finalmente permite asociar el tema de la vejez con la idea de la muerte desde el marco filosófico.
\end{abstract}

\section{PALABRAS CLAVE:}

Envejecimiento, longevidad, vejez, muerte.

\begin{abstract}
In this essay, the author reflects on the topic of aging and its focal relation to the idea of death. The author integrates historical and scientific information and then complements a philosophical assessment. This is the aim of this essays. In the first part, the different conceptions of aging that have prevailed over time are explained, emphasizing the paradigmatic cases antagonistic as Plato and Aristotle, who would later central to the present. In the second part, a brief discussion of the concepts of longevity and aging, which finally allows him to associate the theme of old age with the idea of death from the philosophical framework is done as a question.
\end{abstract}

\section{KEY WORDS}

Aging, Longevity, Old edge, Death.

* Docente de la Facultad de Teología Pontificia y Civil de Lima: mjimenezal@hotmail.com 
El envejecimiento es la única afección fatal que todos compartimos. Leonard Hayflick

La anciana de posguerra, María del Carmen Soler, ha dicho que "hagamos lo que hagamos, estamos siempre en actitud de despedida". Efectivamente, desde que se nace -más precisamente desde la concepción- se está genéticamente orientado hacia un final inexorable. Lanzados como un proyectil, como pensaba Ortega y Gasset, la vida humana se convierte en proyecto finito y diverso. Desde este contexto se podría preguntar en qué consiste ese proyecto, hacia dónde se debe dirigir o está previamente encaminado, cuáles son sus alcances y, sobre todo, cuán sensato es planteárselo. Sin duda, la cadena de preguntas nos conduce a inquietudes metacientíficas, de interés filosófico suscitadas del hecho y la fatalidad misma del vivir; de esa preocupación inmediata de las ciencias particulares y especializadas. Aunque no se pueda contar con respuestas definitivas o últimas, su búsqueda tal vez sea la única esperanza racional con la que cuente el hombre en el camino temporal de su existencia. Si su natural recorrido se sustrae a los accidentes, el porqué del sentido del envejecimiento y de la muerte cobra entonces un particular valor en el proyecto humano de vivir y acabar como tal. Tema que llama la atención no solo a los filósofos, sino también a los humanos hombres de las ciencias de hoy.

El propósito de este ensayo consiste, por tanto, en elaborar una reflexión en torno al tema central del envejecimiento y su relación con la idea de la muerte. Para ello integraré a la información histórica y científica, la complementaria ponderación filosófica. Describiré, en un primer momento, brevemente las concepciones de la vejez en algunos autores y épocas para mostrar luego su concepción más actual. En un segundo y último momento, después de unas discriminaciones conceptuales, vincularé el tema de la vejez con la idea de la muerte.

\section{1}

Precedida de la etapa prenatal, infancia, niñez, adolescencia, juventud y adultez, la vejez viene a ser el séptimo y último estadio del desarrollo natural de la vida humana, desencadenándose luego la muerte. Es en este contexto del ciclo vital de la temporalidad humana, que en la historia del pensamiento sobre la vejez se han concebido, desde la antigüedad, dos posiciones antagónicas: una platónica y otra aristotélica. (Carbajo, 2008). En la obra la República, Platón muestra una concepción positiva sobre los ancianos. Piensa que es la etapa en que el ser humano alcanza las más óptimas virtudes morales, tales como la prudencia, la sagacidad, la discreción y el buen juicio. Todo lo cual, lo habilita además para desempeñar con autoridad los más altos cargos públicos, administrativos, directivos, jurisdiccionales y gubernamentales. La calidad de vida y virtudes logradas en la vejez, según el filósofo ateniense, están determinadas por la forma cómo se ha ido preparando durante la juventud y la adultez.

El punto de vista opuesto, el negativo, lo presenta el teórico de las virtudes, Aristóteles. Concibe la vejez como una etapa de debilidad, deslustre e inutilidad para la vida social y, por tanto, merecedora de compasión. En la Retórica (II 13, 1389b 15-20) en particular, en unas pocas líneas, destaca incluso su menudo perfil psicológico: como de mal carácter, veleidoso, desconfiado, mezquino (también en Ética a Nicómaco, $1121 \mathrm{~b} 13)$, cobarde asimismo frío, egoísta, desvergonzado (idem., 1128 b 
20), pesimista, cobarde y hasta charlatán Frente a los jóvenes aparece además como colérico, débil y esclavo del interés. Vive del "cálculo racional que con el talante, puesto que el cálculo racional es propio de la conveniencia y el talante lo es de la virtud" (Retórica 1389b 15), no comete desmesura sino injusticias vinculadas a la maldad; son también quejumbrosos y sin buen humor. Pero es en Reproducción de los animales, donde Aristóteles identifica la vejez con la enfermedad: "Es correcto decir que la enfermedad es una vejez adquirida, y la vejez, una enfermedad natural" (784b 30). De modo que vivir joven o adulto (madurez para el Estagirita) se puede considerar un bien o una virtud. Esto se debe, a estas dos posiciones en torno a la vejez, las que se van a prolongar en diversos autores, con distintos matices y moderaciones, y que explican además los estigmas vigentes también en la sociedad moderna.

Sin embargo, es De senectute o Diálogo sobre la vejez el primer tratado filosófico sobre el tema del envejecimiento natural en la historia de Occidente. Su autor, el filósofo romano Cicerón, viene a ser por eso el primer gerontólogo de la antigüedad en sentido amplio, toda vez que destaca la calidad y estilo de vida mejores que le corresponde vivir al ser humano en sus años finales. Cicerón, documentado con ejemplos de personajes históricos del mundo antiguo y romano, destaca y elogia la senectud, descarta cualquier sentimiento de compasión por el de respeto y veneración. Sus cualidades mentales o virtudes del intelecto como la dignidad alcanzada son la prolongación de una biografía así llevada, que le ha aportado además amistades en el tiempo. Por eso, cree Cicerón que la amistad en esta etapa es una manera de alejar el aislamiento y la soledad. Alaba pues, la vejez que se edificó en una buena juventud.
Es en la época de Agustín de Hipona como en el medioevo, cercanas a la influencia helénica, donde aún las concepciones antagónicas conviven abiertamente. El obispo de Hipona haciendo coincidir la posición platónica con la visión bíblica, realza la figura del anciano, revestido de dignidad y sabiduría, y en este sentido modelo y guía de vida y de enseñanza. Mientras que Tomás de Aquino muestra su aristotelismo subrayando el egoísmo solitario de la senilidad como su decadencia física y moral.

En el Renacimiento, que busca recuperar la sobriedad y estética grecorromana, se da una aversión a lo viejo y caduco, no clásico, por eso también a la vejez, a lo que se suma asimismo la muerte. No obstante, de cierta tendencia a atribuirle artimañas y prácticas supersticiosas, en general, hay una imagen melancólica y algo sabia de su condición. En el Barroco, por el contrario, no se trata de una etapa desapercibida, sino que se cree que es el período en donde el ser humano muestra lo que ha debido honrar en su inacabada perfección humana: las virtudes, libres de pasiones y de vicios que deshonren su condición y le provean de una buena muerte.

Por otro lado, Schopenhauer (2001, p. 220) en sus aforismos critica que la enfermedad y el aburrimiento sean signos de la vejez puesto que no es un rasgo esencial: Crescente vita, crescit sanitas et morbus. Y el aburrimiento aparece solo a quienes han disfrutado de los deleites de los sentidos y de la vida social, y no han alimentado su espíritu y fuerzas intelectuales. Como Schopenhauer, Shakespeare, Hördelin y Humbolt comparten una visión favorable sobre la vejez sin reconocer sus naturales dificultades. 
En el siglo XX el escritor de lengua alemana, quien falleciera mientras dormía a los 85 años, Hermann Hesse, en su obra Elogio a la vejez, aprecia también favorablemente este período afirmando que tiene tantos achaques como ventajas: "Una de ellas es la capa protectora de olvido, de cansancio, de afecto, que se interpone entre nosotros y nuestros problemas y sufrimientos. Puede ser desidia, anquilosamiento, odiosa indiferencia; mas, vista con otra luz, puede significar también serenidad, paciencia humor, alta sabiduría y Tao." (p. 60). Hesse valora pues, la vida del anciano que la cree además con una tarea propia como la tiene cualquier otra persona a cualquier edad.

Pero en la década de los 70 , es la filósofa francesa, discípula y compañera de Jean Paul Sartre, Simone de Beauvoir, la que escribe un extenso ensayo titulado La vejez (2013). Allí, sobre todo, a propósito de esta, se preocupa de la mujer anciana. Observa que ninguna mujer valora su vejez con complacencia y critica su condición de tabú en Estados Unidos y en la propia Francia, motivos suficientes -confesados ya entrada en años-, que la condujeron a escribir dicha obra con el fin de "quebrar la conspiración del silencio" sobre el tema. La filósofa destaca principalmente su crítica a la actitud negativa de la sociedad para con los ancianos, que impide que estos sean también incapaces de valorarse y crear su propio nicho existencial, por así decirlo.

En conclusión, las reflexiones filosóficas y de las plumas de la literatura ensayística sobre la vejez han sido diversas y abundantes, nacidas unas desde la generalización ejemplar del pensamiento o de textos que hablan de otros textos, y otras surgidas de la propia experiencia y la observación. La orientación general, al parecer, se ha ido inclinando en el tiempo a una actitud mental más conciliadora, tolerante y favorable con respecto no al rol del anciano - que sin duda lo tendría-, sino al hecho de existir y ocupar un espacio en la vida social. Todo lo que se haya dicho desde el pensamiento y los textos sobre la vejez corresponden, en sentido amplio, a la Gerontología, entendida como la promoción de los cuidados y salud del anciano. Mientras que la Geriatría, por su parte, se presenta como la especialidad médica que se ocupa de su prevención y enfermedades.

Es así que su historia, que es historia de la investigación científica sobre el envejecimiento, se inicia recién con la obra de Francis Bacon, Historia de la vida $y$ de la muerte (Carbajo, p.243). La tesis central en ella sostenida es que la vida humana sería longeva si se atendiese y mejorase las condiciones sociales, de higiene y médicas. Es curioso observar que es un filósofo inglés del siglo XVI que se ocupara de este tema en los albores del descubrimiento del método científico, cuando varios siglos después de su inicial interés los científicos propiamente dichos no se preocuparon por el tema por considerarlo falto de interés como intratable (Hayflick, 1999, p. 49-50), sin duda, llevados por los prejuicios vertidos en la historia del pensamiento y de las sociedades principalmente occidentales.

Sin embargo, no siempre fue así. La tardía preocupación científica empezó durante la primera mitad del siglo XX cuando los científicos vueltos de la posguerra despertaron su interés por el fenómeno del envejecimiento al ver una población anciana y al haberse hallado cura a diversas enfermedades infecciosas. Occidente empezaba entonces a presenciar el aumento de un número mayor de personas de avanzada edad. Hasta que en 1964 y luego en 1986 aparecen en inglés los primeros textos 
de investigación académica dedicados a la psicología del envejecimiento, a través de un libro y una revista respectivamente (Carbajo, p. 252).

\section{2}

Antes de partir de una definición estándar de envejecimiento, quisiera comentar primero la afirmación del médico norteamericano Leonard Hayflick (1999): "Los esfuerzos por alargar la vida son en verdad intentos de engañar a la Madre Naturaleza" (p. 61). Esta proposición parte del supuesto de que en la naturaleza no solo hay un orden que configura nuestro tiempo de vida normal y natural como especie humana o simplemente vida orgánica. Alargar la vida resulta entonces una creación o producto deliberado de la civilización, algo específico del homo faber, creador de la ciencia y de la tecnología, los mediadores culturales que hacen posible la longevidad humana y de otras no humanas. Es esto lo que representa pues, un engaño para el orden natural o salvaje de la vida escindida de la civilización. Por la misma razón, se puede decir que el hecho del envejecimiento de los animales responde a esta misma mediación civilizadora que, ya sea en el ámbito doméstico o el del cautiverio (Hayflick, 1999, p. 59), ha permitido que la especie animal -asimismo vegetaltenga una existencia larga. Los animales difícilmente envejecen. No es que la vida biológica no envejezca, sino que habitualmente no había sido así, es decir, la llamada madurez de las especies con frecuencia no se alcanzaba por encontrarse expuesta a la lógica evolutiva de la depredación y la supervivencia, de modo que sigue siendo difícil que un animal cualquiera llegue a envejecer más allá de su etapa reproductiva: morir jóvenes es lo natural en la vida silvestre. El hombre, al margen o al haber reducido esta condición ha llegado, por tanto, no solo a experimentar los cambios propios de la vejez, sino también a prolongarla ampliamente.

Con lo dicho, paso ahora a tratar de responder a tres preguntas. Una vinculada con la longevidad, otra con el envejecimiento y la última con la muerte. Estas son: por qué vivimos el tiempo que vivimos, por qué nos hacemos viejos y por qué morimos. Se trata de tres aspectos fundamentales de la finitud de la vida (Hayflick, 1999, p. 53-54).

El concepto de longevidad hace referencia a la duración de la vida de un ser humano o, en general, de un organismo biológico, lo que también suele llamarse esperanza de vida. Corresponde pues, por un lado, al tiempo que puede esperarse que un organismo viva $\mathrm{y}$, por otro, a sus mejores condiciones de vida. En otro aspecto, tiene relación con los estudios demográficos.

La Organización Mundial de la Salud (2013) ha declarado como un «acontecimiento sin precedentes» en la historia de la humanidad, el hecho de que la población planetaria esté envejeciendo de forma acelerada: del período que va del 2000 al 2050 se calcula que la mayor cantidad de población mundial mayor de 60 años será el doble, y la cantidad de personas octogenarias y más aumentará hasta casi cuatro veces.

Asimismo se ha calculado que en los países desarrollados el promedio de esperanza de vida para los humanos recién nacidos está alrededor de los setenta y cinco años, y la longevidad máxima en unos ciento quince años. Definitivamente, estos datos siempre serán relativos a las condiciones individuales, sociales y de la época en que la cultura y la ciencia aportan cada vez más. Con lo que se quiere decir que actualmente se puede 
ver con claridad que la humanidad ha ido en un aumento mayor en la línea de la longevidad. Incrementándose, por cierto, los requerimientos de profesionales dedicados a la prevención y cura de los ancianos, como de establecimientos y espacios propios de entretenimiento y vida saludable que haga posible su normal desarrollo vital. Quizá sea por esta misma razón que estos países cuentan con la mayor cantidad de personas longevas.

Estos hechos pueden, sin embargo, noticiarnos acerca de dos cosas: que los niños en adelante no solo podrán conocer a sus abuelos paternos y maternos, sino también que serán capaces de compartir con sus bisabuelos, en particular, con las bisabuelas considerando que las mujeres alcanzan un promedio de vida de seis a ocho años más que los hombres. Pero además nos informan, en general, de una posible mejora en las políticas de salud pública y de desarrollo económico, de un posible e inexorable aumento de demencia senil, como es el caso del Alzheimer, y de una notoria disminución de la tasa de fecundidad a nivel mundial. Todo lo cual indica que la población juvenil cada vez deberá entonces estar preparada y formada para convivir dignamente con la gente en edad provecta.

Por otro lado, un concepto difícil de delimitar por los distintos criterios que se esgrimen, es el de envejecimiento. Existen al respecto dos nociones preponderantes y estrechamente ligadas. Desde el punto de vista biológico, el envejecimiento se identifica con un proceso natural del desgaste y la disminución del funcionamiento eficaz de órganos y tejidos (Martínez, 2005, p. 2) que conducen finalmente a la muerte. En este sentido primario guarda relación directa con la herencia genética, a la cual se suman los aspectos psicológicos, sociales y ambientales en que se desenvuelve la vida. Desde el punto de vista funcional se le concibe como la pérdida de las funciones normales a nivel físico, psíquico y cognitivo que incapacitan para realizar actividades cotidianas de manera independiente. Es esta segunda acepción la más habitual en el ámbito de los profesionales de la salud y la más popular entre la gente; para algunos, rezago de una concepción desafortunada y actualmente bastante discutida (Martínez, 2005). En efecto, la observación se centra en hacer coincidir el envejecimiento con la muerte al ponerse énfasis en la posibilidad de padecer enfermedades crónicas de alto riesgo y en la discapacidad física motora. Sin duda, esta visión crea asimismo un imaginario social que estigmatiza la figura y presencia del anciano, cuando ello es producto de un prejuicio socializado. Las enfermedades crónicas o no como, por ejemplo, la depresión no es un estado distintivo de la vejez, lo pueden ser de cualquier etapa del desarrollo humano.

Si de inmediato tuviéramos que responder a la pregunta de por qué se envejece, las dificultades para responder correcta y satisfactoriamente aumentan. Al respecto se ha intentado contestar por medio de teorías, que ya son muchas, unas más especulativas que otras, y otras que aspiran a tener un sustento en la investigación científica. En general, siguiendo la relación estipulada por Hayflick (1999, pp. 295-341), podríamos clasificarlas en aquellas fundadas en fenómenos finalistas y las fundadas en fenómenos aleatorios. Las primeras, cuyas reflexiones provienen de los biogerontólogos, tienen la debilidad en su juventud como ciencia nueva que las hace muy limitadas para llegar a resultados más convincentes. Estas teorías tales como la de la sustancia vital, la de la mutación genética, la del agotamiento reproductor y la endocrina pero, en particular, las tres 
primeras se basan en ideas antiguas y en juicios más emocionales que racionales, como en los prejuicios de sus defensores. Por ejemplo, la teoría de la sustancia vital responde que el envejecimiento se da debido al agotamiento de dicha sustancia, con la cual uno nace con una medida determinada, pero que al pasar el tiempo ésta merma hasta que su ausencia produce la muerte. Estas teorías conciben al organismo humano como un reloj biológico, y se las llaman finalistas porque presuponen un diseño o plan maestro que activan al final los «genes de la muerte» a nivel químico y físico de moléculas específicas que desencadenan el proceso del envejecimiento hasta su finitud.

Las denominadas teorías aleatorias o casuales conforman el grupo opuesto a las finalistas, y sostienen en general que el envejecimiento se produce de manera accidental sin ninguna programación preexistente. De este modo pueden atribuir el proceso de envejecer a fallos en las moléculas del ADN, al desgaste natural o a la aglomeración de desechos. Estas teorías son muchas: la del ritmo de vida, la del entrecruzamiento, la de los radicales libres, la del sistema inmunitario, la de errores y reparaciones, la del desgaste natural, la del orden que se desordena. Esta última, por ejemplo, se basa en los estudios de la Física. En este sentido, explica el envejecimiento como un proceso de desorden general: desde la concepción, el organismo humano se orienta hacia la madurez sexual, luego de ésta las moléculas que hicieron posible la madurez reproductiva inician un camino de deterioro, el desorden se instala y aumenta, se vincula pues con el concepto físico de entropía que hace referencia a la segunda ley de la termodinámica.

De lo dicho, no es posible aún pronunciarse a favor de ninguna teoría, ni sostener razonablemente que algunas de ellas son más válidas y consistentes que otras. Desde el punto de vista científico, todavía no es posible validar un resultado, pero en la medida de que la investigación científica sobre el envejecimiento ha ido incorporado también el interés y trabajo de los biólogos, se espera que la ruta especulativa cederá finalmente a la investigación empírica.

El profesor de anatomía Leonard Hayflick (1999, p. 338-341) cree, sin embargo, tener un punto de vista más personal frente a las teorías presentadas, sin dejar de ser deudora de algunas de ellas. Basándose en el proceso evolutivo y en el desarrollo de la madurez sexual afirma que de ésta no se sigue directamente el envejecimiento, sino que se da un período de conservación de energía suficiente para que se pueda aún criar a la prole, luego de lo cual tampoco se da un camino acelerado de desgaste, sino que se trata de un proceso lento y entrópico hacia la muerte. Pero, aún con todo, Hayflick es consciente de que su explicación no deja de inscribirse en el ámbito de lo probable y que requiere todavía de mayor información e investigación que lo avale suficientemente.

Se puede decir, finalmente, que todas estas teorías responden más específicamente a la pregunta de qué sucede cuando se envejece que al por qué se envejece, que es la pregunta del mayor interés filosófico y científico para cualquier humano del siglo XXI.

Resta, por tanto, dilucidar el tema de la vejez con el de la muerte. En principio, se puede decir que no existe un vínculo natural. Envejecer entonces no mata. Uno muere por accidente, en cualquiera de sus formas fortuitas o tentadas, o por enfermedad, pero no de viejo. Un cáncer, por ejemplo, no es una enfermedad 
propia de la vejez como tampoco lo es la ceguera, ni cualquier otra enfermedad de índole terminal. El deterioro orgánico es parte de un proceso del envejecimiento pero no todo, hay otros aspectos que las definiciones ortodoxas no siempre toman en cuenta, como los psicológicos, cognitivos y sociales que no coinciden con un desgaste biológico. La lucidez y agudeza mental permanentes en muchos ancianos son ejemplos palmarios de no envejecimiento de la totalidad de la persona.

Sin embargo, podría considerarse, por otro lado, la merma de la capacidad física como una etapa de preparación hacia la muerte. Al respecto ha dicho Schopenhauer: "La mengua de todas las fuerzas conforme va avanzando la vejez es muy triste, pero también algo necesario e incluso favorable, pues de lo contrario la muerte, de la que es el preludio, sería demasiado difícil" (2001, p. 221).

El filósofo del pesimismo, al parecer, no lo es del todo en este caso. No identifica la vejez con la muerte, sino con la degradación de la fortaleza física que le resta autonomía. Pero el filósofo está pensando además en la muerte como un acontecimiento saludable, incluso, se podría decir, desde el punto de vista social. En efecto, con frecuencia cuando alguien nace está rodeado de la alegría de quienes esperan y acompañan el evento. Lo mismo podría ocurrir con la muerte, esperarla significaría también estar acompañado para la partida como Sócrates en sereno diálogo, aunque podría ser también con una ecuánime tristeza o un taciturno llanto, puesto que: "El mayor premio que otorga una excesiva longevidad, es precisamente, la eutanasia, esto es, la muerte sin padecimiento ni dolor, enormemente fácil, exenta de espasmos y libre de enfermedad alguna" (Schopenhauer, 2001, p. 221).
Sin duda, la reflexión del filósofo ha partido de supuestos, obvios hoy en día, tales como el programa de una vida cuidada desde temprana edad, con un orden y disciplina que orienten hacia el bienestar de todas las facultades: y llegar a ser lo que, en el lenguaje de la gerontología actual, se ha venido a denominar una vejez competente y activa (Rodríguez, 2010, p. 20). Ello no niega, sin embargo, que por el proceso mismo haya, efectivamente, un deterioro de las facultades más cuidadas en los más longevos, sino que no debería ser confundido con el deterioro patológico que es de otra índole. Desde esta distinción entonces, se hacen perfectamente comprensibles el sentido de los versos del viejo Hessen:
Penosamente se arrastra a lo largo de su larga noche, aguarda escucha y vela.
Ante él descansan sobre la colcha sus manos, la izquierda y la derecha, rígidas y tiesas, servidores cansados.
Y ríe
suavemente, para no despertarlas (2001, p. 72).

Quizás sea especialmente en la vejez en que la meditación sobre la muerte no solo sea una constante $-\mathrm{y}$ la mejor etapa para reflexionar sobre el sentido de la propia condición- sino asimismo uno de los mejores legados de orden filosófico para la cultura y posteridad de las naciones. No digo desde el punto de vista científico porque la meditación, cualquiera sea su contenido, no se puede evaluar por medios cuantitativos y convencionales, aunque haya habido intentos de investigaciones serias desde la investigación psicológica; lo cierto es que hasta el momento solo se ha recurrido a procedimientos cualitativos y a la aplicación de diversas técnicas difíciles de tipificar y estandarizar (FernándezBallesteros et al., 2007, pp. 210-215). Por otro lado, estos estudios no hacen, 
por ejemplo, plena justicia -en el caso de atribuirla favorablemente a la vejeza los distintos conceptos de sabiduría contemplados en la historia de la filosofía. Cuando en una ciencia particular no se tiene claro los conceptos es común recurrir a determinadas teorías que la expliquen, o bien acercarse a la gente de lo cotidiano a averiguar su sentido y usos. En este aspecto se puede comprender, en parte, la enorme dificultad de partir de un concepto estándar de sabiduría que pueda ser útil para emprender una investigación precisa.

Sin embargo, se podría asimismo centrar mejor el interés por la relación entre la vejez y la sabiduría desde la filosofía misma. Si se admite como cierta la afirmación de que el ideal de la vejez es la sabiduría en un organismo mentalmente sano, la pregunta que surgiría es si esta llega a ser, por tanto, un atributo propio. Para liberarse del prejuicio griego y de la historia de la filosofía en general, de que la sabiduría es una propiedad del anciano que se ha preparado, existe en contraparte un informe actual que relativiza razonablemente la respuesta (Fernández-Ballesteros et al., 2007, pp. 213-214). No se trataría pues, de un atributo exclusivo, sino que se lo puede encontrar además en el joven y en el adulto, pero en menor medida, y hasta cualitativamente distintos dado el elemento fundamental de la experiencia de vida, por lo que se la puede tipificar normalmente en la vejez. Ello implica no considerar la sabiduría como un saber más, sino un saber esencial -y tal como indica su etimología- un saber del cual se disfruta, pero comporta un sereno gusto para el pensamiento que excede la propia reflexión y centra su temática fundamental. La sabiduría comprende entonces un tipo de meditación sobre cuestiones vitales de la existencia y finitud humanas, con una capacidad de orientarla y saber vivirla a cualquier edad de la vida, y especialmente en su período de partida. Diría incluso que es un estadio en donde se zanjan las conclusiones del propio camino recorrido que se complementa con un tiempo de acogida y elocuente contemplación.

Y aunque la muerte como preocupación no sea un tema común en las primeras etapas de la vida es, no obstante, culturalmente de interés variado a cualquier edad. En los niños, por ejemplo, se puede constatar que se la toma sin drama ni preocupaciones, y de forma directa e intelectualmente casi neutra; pero en edades avanzadas se va formando sobre ella el respeto, la evasión o el silencio: "El homo faber oculta la realidad de la muerte" (Yepes y Aranguren, 2006, p. 344). El anciano puede contemplar la muerte frontalmente reconociendo su cercanía y aceptando su imponente misterio.

La vejez puede entenderse pues, como la ocasión de pensar la propia condición y la meditación saludable que prepara hacia una sabia muerte, mejor dicho, la propia muerte. De lo contrario sería una vejez sin contenido y una muerte sin sentido, quizás representados en los versos de Baudelaire: "Me voy de espaldas a acostar,/ $y$ en vuestros velos a ocultar,/ ioh tinieblas refrigerantes!" (1972, p. 201). Sería, por tanto, la etapa de un natural y particular estado filosófico, que no se puede reducir al mero pensar, sino a comprender la vida desde la propia reflexión, biográfica y experiencial. Se trataría de una filosofía vital que paradójicamente orientaría el tiempo previo a su impermanencia. 


\section{REFERENCIAS}

Aristóteles. (1994). Reproducción de los animales. Madrid: Gredos.

Aristóteles. (1994). Retórica. Madrid: Gredos.

Baudelaire, Charles. (1972). Las flores del mal. Buenos Aires: Losada, S.A.

Carbajo Vélez, Mª del Carmen, «Historia de la vejez», en Ensayos, 2008 (18), 237 254. Recuperado el 18 de noviembre de 2013 de http://dialnet.unirioja.es/ descarga/articulo/3003504.pdf

Cicerón, Marco Tulio. (1982). De la vejez, . México: Porrúa, S.A.

De Beauvoir, Simone, La vejez. Extracto, recuperado el 20 de noviembre de 2013 de https://docs.google.com/ file/d/0B77IcJbn8X9LNTRkOGYwYmE tMDhlMi00OWQ4LWJjZmYtMzAyZDBI ZGQzYzQw/edit?usp=drive_webEsor $\mathrm{t}=$ nameElayout $=$ list $\mathrm{Epid}=0 \mathrm{~B} 77 \mathrm{IcJ} \mathrm{b}$ n8X9LYjg3MjAzOGUtZDBkNi00M2E5 LWJhOTktMDVmYjlhMDdkZTYxEcinde $\mathrm{x}=22 \varepsilon \mathrm{Eli}=1$

Fernández-Ballesteros et al. (2007). Qué es la psicología de la vejez,. Madrid: Biblioteca Nueva.
Hayflick, Leonard. (1999). Cómo y por qué envejecemos. Barcelona: Herder, S.A.

Hesse, Hermann. (2001). Elogio de la vejez., Barcelona: Muchnik Editores, S.A.

Martínez Martín, María Luisa. (2005). Vejez y envejecimiento. Recuperado de http://www.uam.es/personal_pdi/ elapaz/mmmartin/2_asignatura/temas/ unidad1/2/tema2.p $\overline{d f}$

Organización Mundial de la Salud. (2013). Envejecimiento y ciclo de vida. Recuperado de http://www.who.int/ ageing/about/facts/es/

Rodríguez Daza, Karen Dayana. (2010). Vejez y envejecimiento. Bogotá: Universidad del Rosario, Escuela de Medicina y Ciencias de la Salud. Recuperado de http://www.urosario.edu.co/ EMCS/Documentos/investigacion/ d ocum en tos Investigacion / Documento 14/

Schopenhauer, Arthur. (2001). Aforismos sobre el arte de saber vivir. Madrid: Debate, S. A.

Yepes, Ricardo y Javier Aranguren Echevarría. (2006). Fundamentos de antropología. Un ideal de la excelencia humana. Pamplona: Ediciones Universidad de Navarra, S.A. 